\title{
Enriching health research through consumer involvement - learning through atypical exemplars
}

\author{
Carla Saunders and Afaf Girgis
}

\section{Introduction}

Health science is primarily based on ideas created in academic environments which are then tested and described in scientific papers with a relatively small proportion going on to be delivered to health care consumers. ${ }^{1,2}$ Generally, the people participating in or affected by the research activities meant to benefit them have little or no input in the research, either in determining what is to be investigated, the types of information obtained or in defining the measures of success. ${ }^{3,4}$

Internationally, consumer involvement in research has reportedly resulted in a range of benefits including securing funding, changes in research aims, design, outcome measures and content of participant consent and information resources to ensure they are more relevant, user-friendly and ethically acceptable. ${ }^{5-10}$ Consumers have also supported improvements in the development of data collection tools and have advantageously informed and undertaken data analysis, and disseminated research findings to the wider community. ${ }^{11-14}$ There are a few leading areas, such as the disability and AIDS movements, that have been instrumental in advancing consumer involvement in health research. ${ }^{15-17}$

Australia has a model framework which broadly guides a coherent approach to involving consumers in health research. ${ }^{18,19}$ The existence of a model framework in any field recognises the importance of that field, and is often evidence of seminal thinking in itself. At a minimum, Australia's Model Framework is intended as a resource to provide advice and practical information to support and promote consumer participation in research in Australia. The application of any model framework is subject to operational realities and constraints. ${ }^{19}$ There is a lack of formal reporting of the application of the Model Framework so the effectiveness and utility of it, and its components, in facilitating consumer and community involvement in health research, are difficult to gauge.

This investigation has two major goals: to examine in detail a purposive sample of organisations and describe how each has applied consumer involvement approaches across a range of purposes and contexts in Australia; and to collectively analyse the purposive sample in relation to Australia's Model Framework to assess its utility when implementing consumer involvement in research.

The intention of this paper is not to establish or sanction particular approaches to consumer involvement in health research but to highlight a broad range of examples of involving consumers in research which it is hoped, in turn, will allow other organisations that may have the desire but not the know-how or knowledge of the breadth and variety of options for involving consumers. There is currently an absence of an Australian study of this nature in the academic or 'grey' literature.

\section{Abstract}

Objective: The goal of this exploratory study was to identify and describe notable cases of consumer involvement in Australian health research to generate insights and concepts, and assist others to develop and build capacity in this area.

Methods: In-depth interviews were conducted with nine organisations known to be active in this area. The interviews were supplemented with content analysis of relevant documentation to further examine involvement strategies.

Results: Key attributes that aid consumer involvement competence and contribute to success in this area are identified, including the availability of time, resources and supporting policies, principles and attitudes that securely back opportunities for consumers to be involved in meaningful ways.

Conclusion: This study provides an important contribution to our knowledge and understanding of consumer involvement practice in Australian health research. The examples do not offer definitive approaches but rather highlights and lessons drawn from experiences in consumer involvement across a diverse range of organisations.

Key words: sociology, consumer, involvement, health, research

Health Promotion Journal of Australia 2011; 22: 196-202

\section{So what?}

Accessing the valuable reserve of knowledge that can be found within the context of lived experiences and felt need, with the aim of improving the relevance and translation into the practice of Australian health research is timely, given the heightened political importance of reducing health care costs and the need to support growing numbers of people with chronic illness. 


\section{Method}

This study was conducted over a five-month period from September 2009 to January 2010 and received ethics approval from the University of Newcastle's Human Research Ethics Committee (Reference No: $\mathrm{H}-2008-0030)$

\section{Study sample}

An in-depth phone interview was conducted with a sample of Australian organisations that were selected in a deliberative fashion to represent a range of experiences in consumer involvement in research. The organisations invited for interview were identified through the findings of research undertaken by the authors, including a survey of Australian research and research-funding organisations investigating consumer involvement. ${ }^{20}$ They were selected because they were known to be actively and creatively involving consumers in health research. The particular selection was made deliberately diverse to enhance the robustness of the information gathered and support the conclusions drawn from the study. Twelve organisations that varied appreciably in structure, focus and processes were selected.

\section{Procedure}

An initial contact person (the CEO, manager or a senior researcher) was identified for each of the final selected organisations. An invitation to participate was sent to the identified contact in an e-mail which also contained the approved study information sheet and consent form.

Organisations that took up the invitation to participate in the study were invited to provide any written material they considered would support the researchers' understanding of their particular consumer involvement strategies. Participant organisation websites were also content-analysed to support an understanding of organisational context and provide a sense of the organisational features that may be required to implement particular consumer involvement strategies.

In-depth interviews of 45-60 minutes were conducted by phone during which time detailed notes were taken. The interviews focused on the organisations' broad experiences with and attitudes toward consumer involvement in the organisations' governance and individual research projects. General interview questions were included, such as: a request for verbal descriptions of and rationale for initiatives; stakeholder experiences; the impacts on the organisation of involving consumers; difficulties encountered and perceived advantages of the activities. The interviews were otherwise conducted in a manner that allowed free-flowing discussion. In-depth interviews are optimal for collecting data on individual histories, perspectives, and experiences, particularly when multifaceted topics are being explored and where flexibility is needed to allow for probing of participant responses to harvest further information. ${ }^{21,22}$

The research was premised on full disclosure of participant organisations and persons involved to enable contact by other groups and people interested in establishing consumer involvement in health research. All participants viewed the paper prior to submission and have given permission for their contact details to be provided in the acknowledgment section as key informants.

\section{Analysis}

Written transcripts, website information and any other documentation provided by each participating organisation on their consumer involvement activities were examined to enable a clear description of each and determine the factors that seemed to underpin consumer involvement competence in the selected organisations.

Recurring factors were developed into a coding scheme to classify the major emergent themes. To identify if any revisions were needed, the coding scheme was tested on two participating organisations against their phone transcripts, website and other information before applying it to the remaining examples.

\section{Results}

Representatives from nine of 12 key organisations agreed to participate in the study. Table 1 provides a brief profile of each participating organisation, with relevant website links to allow liaison and further investigation. The three organisations that did not agree to participate did not reply to the initial and subsequent e-mailing.

This paper describes both common findings and individual initiatives. Key activity areas which appear to aid consumer involvement competence in organisations and contribute to success in this area have been identified and are explained using exceptional examples from our findings.

\section{Governance}

Deliberative approaches employed by governance structures within the participating organisations, i.e. the people and committees that had control over decision-making processes, were found to be key factors in an organisation's success in this area.

\section{Australian innovation}

The Depression and Anxiety Consumer Research Unit of the Australian National University ${ }^{23}$ was purposely developed in 2003 to focus on the unmet research needs, and health and social issues of mental health consumers. The unit, a world first, identifies and undertakes research from the perspective of those with the common mental illnesses and it is staffed, through targeted recruitment and retainment processes, by academic researchers and students who are also consumers; that is, they have personal experience of a diagnosis of depressive or anxiety disorders. The unit recruits those who have the necessary skills, are willing to be open about their experience and wish to incorporate their lived experience of mental illness into their work.

The Cooperative Research Centre for Aboriginal and Torres Strait Islander Health (CRCAH) 24,25 has responded to a general Aboriginal community apprehension about health research to develop a funding process that ensures research targeting their communities provides benefits to and is controlled by Aboriginal people. In informing the approach, community members called for genuine research partnerships between researchers and communities that would build on Aboriginal self-determination and cultural respect rather than being focused on the priorities and career objectives of researchers and not contributing sufficiently to health improvements. Potential users of research are involved throughout the research and the early identification of priorities with community and other 

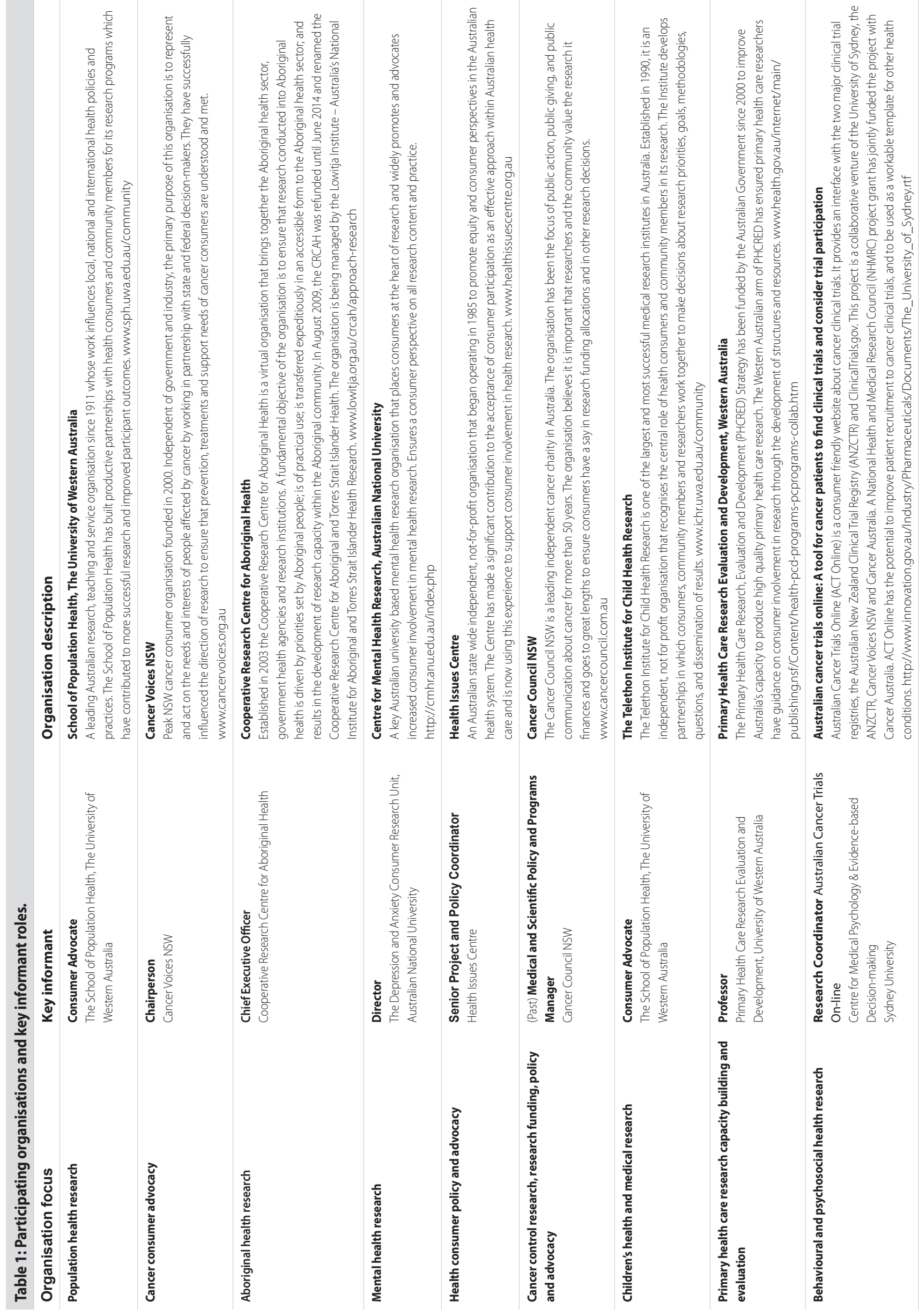
stakeholders, and close ongoing associations with project teams ensure that the practical application of research are much more likely.

\section{Structures}

Concerted efforts for consumer involvement through the establishment of shared supportive structures were found to exist between two of the participating organisations. The Telethon Institute for Child Health Research Consumer and Community Advisory Council ${ }^{26}$ is supported by the Consumer Advocate from the School of Population Health at the University of Western Australia. ${ }^{27}$ The Advocate works across both organisations and provides regular reports to each. The aim of the Council is to enable the development of partnerships in which consumers, community members and researchers work together to make decisions about research priorities, goals, methodologies, questions, and dissemination of results to make the research conducted by the organisations more relevant to the communities they serve.

Through its Council, the Telethon Institute has established the only associated awards structure in Australia. The Consumer and Community Participation Awards acknowledge good consumer and community participation in research initiatives in the Institute. The criteria used to judge applicants include: that the participation activities support sustainable practices for future consumer and community participation activities; that the participation activities demonstrate a change in practice or processes to incorporate consumer and community involvement; and that the nominee can demonstrate initiatives that provided support and encouragement to consumers involved in their research.

The Primary Health Care Research, Evaluation and Development Unit at the University of Western Australia is the first to establish a Consumer Advisory Group to provide a consumer perspective on General Practice research activities, and advice on consumer issues and priorities in General Practice and primary health care research. This group, which included the Consumer Advocate from the School of Population Health at the University of Western Australia, subsequently developed Guidelines for Consumer and Researcher Engagement in Primary Health Care Research. Examples of how General Practice and primary health care research has involved consumers are available from the Primary Health Care Research and Information Service. ${ }^{28}$

The $\mathrm{CRCAH}{ }^{24}$ carried out major organisational restructuring to ensure the robust engagement of Aboriginal people and organisations in its research processes and programs. Within and across its programs the CRCAH bought together its programs to consolidate efforts and ensure a greater potential for effective consumer involvement and targeted transfer of research into practice. User involvement is built into organisational structures including the Board to ensure engagement with consumers and other stakeholders. The concept of 'linkage and exchange' between researchers and research users underpinned new roles that would connect and broker relationships between all relevant stakeholders.

\section{Policy}

A number of the participating organisations had a comprehensive organisation-wide policy concerning consumer involvement. For example, the School of Population Health in the University of
Western Australia and the Telethon Institute for Child Health Research legitimises consumer involvement in their Consumer and Community Participation Policies. Research practice reflects the requirements of the organisational policies which require: consumers and researchers working together to add value to research; acknowledgement of consumers as key stakeholders in all research; partnerships roles decided through consultation between consumers, community and researchers which are based on mutual respect for one another's different knowledge and experience. ${ }^{26}$ Resources including a practical guide have been developed to support policy implementation. ${ }^{29}$

\section{Research funding}

Cancer Council NSW (CCNSW) ${ }^{30}$ and Cancer Voices NSW (CVN), ${ }^{31}$ a leading cancer consumer advocacy group, have developed a unique approach to ensuring consumers have an influential and sustained voice in research funding decisions. These groups conducted research to assess consumer views on aspects they valued as important in selecting research for funding and as a result, a set of values and associated guidelines were developed for use by a purpose convened Consumer Review Panel to assess and rate research funding applications. ${ }^{32}$ Training and information in the understanding and use of the consumer review criteria is provided to support consumers and researchers. CCNSW reports that the regular consumer review of research by a dedicated consumer review panel relies on the commitment of a range of staff in the development of formal terms of reference, co-ordination, training and management of the consumer panel members, and communicating processes, progress and problems to CCNSW Board and management..$^{33}$

\section{Infrastructure}

A number of the organisations stated that a necessary consideration in consumer involvement in research was actively supporting the development of infrastructure relevant to sustained involvement.

\section{Consumer registers}

A number of participants described the establishment and maintenance of state-wide registers of consumers with experience working in research, advocacy, policy development and other fields requiring consumer representation, and who are interested in being involved in research decision making and support. One highly developed example is that provided by Cancer Voices NSW ${ }^{31}$ which, through its Consumer Nominee to Research Projects Program, has not only established and maintained a register of interested and trained cancer consumers, but co-ordinates and matches individual consumers with relevant expertise to requests for involvement in individual research projects and other research-related activities.

\section{Information}

Apart from establishing and maintaining an up-to-date register of willing, experienced consumers, the Health Issues Centre ${ }^{34}$ recognises the importance of formal and informal support networks and resources and provides opportunities for those involved to share information and advice with others. A web-based library of information resources to support knowledge-sharing among consumers and others interested in consumer involvement is available on their website. Relevant publicly accessible information 
from overseas is also included to ensure comprehensive access to a wide range of information.

The Depression and Anxiety Consumer Research Unit has won awards for community outreach for its important contributions to Internet interventions. Developed as a result of the 2004'Promoting Consumer Participation in Mental Health Research'workshop by the Depression and Anxiety Consumer Research Unit, ${ }^{30}$ the Brolganet website $^{35}$ facilitates an online network of people interested in promoting consumer participation in mental health research including researchers, consumers, policy makers, mental health professionals and others. The site's bulletin board, BrolgaBoard, provides a discussion forum between stakeholders and the resource library contains documents and links to useful resources, including training/educational resources, policy documents and research articles that are relevant to mental health consumer involvement in research.

\section{Capacity}

An organisation's efforts to ensure that researchers and consumers have the requisite attitudes, knowledge, and skills for consumer involvement were viewed as key success factors by the participating organisations.

\section{Consumer training}

Most participating organisations reported mechanisms to ensure consumers are adequately supported through the provision of training, education and resources appropriate to their expected role. The first formal research training for consumers was developed by the Cancer Council NSW and Cancer Voices NSW and has been offered annually since 2005 . Some of the organisations provided support to consumers at the request of other groups. For example, the Health Issues Centre has recently been funded by the Victorian Cancer Agency ${ }^{36}$ to develop and deliver a training program on consumer participation in research for cancer consumers. The main aim of the project is to build the skills and knowledge of cancer consumers to work in collaboration with cancer researchers in Victoria.

\section{Researcher training}

The University of Western Australia's School of Population Health ${ }^{27}$ via its Consumer Advocate has developed a training program in response to enquiries from researchers and students on practical ways to involve consumers in research. During the two-day training, researchers have the opportunity to better understand the contribution consumers and the community can make to research when involved as active partners; identify and address barriers to consumer involvement; explore and develop ways to start involving consumers as partners in their research work, and encourage and support other researchers who may have an interest in consumer involvement in research.

\section{Advocacy}

The majority of the participating organisations actively promote and advocate for greater community understanding of, and consumer involvement in, health research. Acting as ambassadors, they help build an understanding of the valuable role of the consumer in health research and drive important initiatives that may otherwise not be undertaken.

\section{Unmet research need}

The capacity of consumer organisations to identify significant but dormant problems, and arouse support by professionals and nonprofessionals alike, is illustrated in the following example. After long identifying the widespread need for lay information on available cancer clinical trials, CVN co-ordinated input from consumer groups nationwide and brought the level of unmet need to the attention of research groups. The result of this effort led to the development of the Australian Cancer Trials Online ${ }^{37}$ which uses information from two clinical trial registries: the Australian New Zealand Clinical Trials Registry and ClinicalTrials.gov. A consumer representative as a principal investigator and a consumer reference group worked in partnership with researchers throughout the planning, development and testing phases to develop a system that enables consumers and clinicians to quickly and easily search for relevant cancer clinical trials, and to find lay information about each trial and resources to aid participation decisions.

\section{Calls for progress}

In 2008, the University of Western Australia, School of Population Health ${ }^{27}$ and the Telethon Institute for Child Health Research ${ }^{26}$ hosted the first national forum ${ }^{38}$ to discuss and learn about efforts in involving consumers in Australian health research. Almost 250 people attended the forum which found a major barrier to consumer involvement in Australian research to be a lack of support from funding bodies. An important outcome of the forum was the development of a formal communiqué which advocated for a national co-ordinating body and training strategy for consumer involvement in research.

\section{Hints and hurdles}

Apart from discussing specific examples of consumer involvement activity, each study participant was asked two general questions: "If you had the opportunity to advise others on involving consumers in research, what would be your top three tips for making it happen?" and "What were the barriers or operational difficulties you came up against when involving consumers?" The range of participant responses to these questions is provided in Table 1.

Common input from participants was that consumer-researcher collaborations require planning and perseverance and that these partnerships are reliant on comfortable human interaction among not necessarily like-minded people. There is no simple formula for success but allowing adequate time to establish the consumerresearcher partnership and to set realistic terms is important. The findings suggest that partnerships are likely to work best when all parties are clear about their intentions, assumptions, and limitations from the start. Trust is essential, as is quelling any anxieties with regard to roles and other aspects of the partnership such as formal acknowledgements and other expectations.

\section{Limitations}

This study is limited to descriptions of examples of consumer involvement in Australian health research from nine organisations. While we attempted to capture a broad range of prominent consumer involvement programs across a wide range of organisations, our nine may not be demonstrative of all such programs. Furthermore, while the study provides a snapshot of the strategies and success 
indicators reported by key stakeholders in each of the participating organisations, it does not offer all details. To remedy this we have provided organisational details and web addresses to enable further information sharing. Future studies could examine a multiinstitutional sample that includes overseas organisations that are successful in this field.

\section{Discussion}

Our study of selected initiatives shows that a variety of worthy consumer involvement efforts are contributing in creative and innovative ways to inform health research in Australia and provide a number of lessons for those willing to invest their energies and skills in supporting participation. The results indicate that consumer involvement competence can be thought of as a framework of various supporting policies, principles, techniques and approaches that securely back opportunities for consumers to be involved in meaningful ways. Supportive governance arrangements; necessary infrastructure that provides readily available opportunities to involve consumers such as registers of willing and available consumers, and the ability and skill of both consumers and researchers to ensure appropriate involvement were found to be essential for successful involvement.

The findings align with the recommendations provided by Australia's only guidelines in this area, which highlight four fundamental components required for organisational success, ${ }^{26}$ including that:

- Both senior leadership and operational capacity will underpin success in developing consumer participation in research.

- Building consumer participation into the structures of research funding bodies, organisations and teams will strengthen and support its implementation.

- Resources are needed to help consumer participation to work well.

- Developing and sustaining consumer participation requires changes to structures and attitudes, which take time and commitment.

An additional finding of this research, which was not highlighted in the Model Framework, was the importance of systems advocacy among those active in this area, all of whom stated that they work with others to encourage greater community understanding of, and consumer involvement in, health research.

As the large majority of academic publications do not provide descriptions of consumer involvement in research and there is no ongoing case collection to use as 'templates' or 'ideas' to guide increased involvement in Australia, more innovative and promising practices such as those highlighted in this research need to be documented and disseminated in order to strengthen the capacity for consumer involvement in Australia's health research.

Table 2: Hints and hurdles to involving consumers in research.

\section{Hints Organisational development}

Become informed about consumer involvement in all aspects of research.

Gain commitment for consumer involvement from all involved including consumers.

Plan and develop consumer involvement in spite of reservations.

Identify and include the costs of consumer involvement in funding submissions and negotiations for new programs with management.

\section{Leadership and human resource support}

Ensure there is a committed organisational leader who appreciates the usefulness that diverse knowledge has on achieving effective research outcomes.

Identify and support an organisational driver to coordinate the involvement process.

Draft a staff member who has expertise in knowledge bridging to identify and plan functional strategies and support effective partnerships between professionals and consumers

\section{Consumer-researcher collaboration}

Consumer-researcher partnerships require investments of time and patience.

Become respectful of different strengths through adequate training and information for both parties on the potential and practical applications of involving consumers in research.

Spend time on deciding how the partnership will work and be sustained. Identify the preferred approach of consumers for involvement in any research.

Ensure each party's role is well defined and agreed early.

Allow adequate time for activity development and strong relations to be nurtured.

Establish regular checkpoints to determine whether the partnership is working as planned, giving each party the opportunity to recommend changes, voice concerns, and address issues before they escalate.

\section{Hurdles to \\ Comprehension \\ overcome \\ Greater awareness among consumers and professionals of the benefits of consumer involvement \\ Ensuring consumer and researchers place a similar level of importance on the other.}

\section{Resources}

Adequate funding to support appropriate consumer involvement programs and initiatives. Involvement, particularly if it is to involve those who are the most marginalised in our society, requires substantial input of resources to support the process of providing people with the resources and skills they require to effectively take part

Ability to meet the time commitment for the set up and ongoing management of consumer involvement activities and programs.

\section{Expectations}

Misaligned expectations for the results produced by the consumer researcher collaboration.

Assuring each party is successful in the collaboration.

Not losing individual autonomy while joint working and learning take place.

Managing changes in expectations and strategy over the term of the collaboration.

Addressing the increasing expectation of research funders for significant consumer involvement when resources and commitment are in short supply. 


\section{Conclusion}

Knowledge is the key to success in the complex changing environment that underlies effective health care. The distribution of useful knowledge in this area is scattered not only among scientists and other professionals but within the contexts, values and needs of consumers. Many communities and community based organisations have long been involved in health research in different forms without labelling it as such and there are many forms of involvement that go unrecognised as they may be regarded as usual practice. By reaching out to consumers, research organisations may be better equipped to address community concerns and reduce research achievement gaps.

\section{References}

1. Estabrooks CA, Floyd JA, Scott-Findlay S, O'Leary KA, Gushta M. Individual determinants of research utilization: a systematic review. J Adv Nurs. 2003;43(5):506-20.

2. Kvien TK, Mikkelsen K, Nordvag BY. Results from controlled clinical trials: how relevant for clinical practice? J Rheumatol. 2003;30:1135-7.

3. Wykes T. Blue skies in the Journal of Mental Health? Consumers in research. J Ment Health. 2003;12:1-6.

4. Barber R, Boote JD, Cooper CL. Involving consumers successfully in NHS research: a national survey. Health Expect. 2007;10(4):380-91.

5. Thornton H. Edwards A, Elwyn G. Evolving the multiple roles of'patients' in health-care research: reflections after involvement in a trial of shared decision-making. Health Expect. 2003;6(3):189-97.

6. Koops L, Lindley R. Thrombolysis for acute ischaemic stroke: consumer involvement in the design of new randomised controlled trial. BMJ. 2002;325:415-17.

7. BooteJ, Telford R, Cooper C. Consumer involvement in health research: a review and research agenda. Health Policy. 2002;61:213-36.

8. Oliver $\mathrm{S}$, Clarke-Jones L, Rees $\mathrm{R}$, et al. Involving consumers in research and development agenda setting for the NHS: developing an evidenced based approach. Health Technol Assess. 2004;8:1-148.

9. Ali K, Roffe C, Crome P. What patients want: consumer involvement in the design of a randomized controlled trial of routine oxygen supplementation after acute stroke. Stroke. 2006;37(3):865-71.

10. Kirwan JR, Hewlett SE, Heiberg T, Hughes RA, Carr M, Hehir M, et al.: Incorporating the patient perspective into outcome assessment in rheumatoid arthritis-progress at OMERACT 7. J Rheumatol. 2005;32:2250-6.

11. Trivedi P,Wykes T. From passive subjects to equal partners: qualitative review of user involvement in research. Br J Psychiatry. 2002;181:468-72.

12. Staley K, MinogueV. User involvement leads to more ethically sound research. Clinical Ethics 2006;1:95-100.

13. Staniszewska S, Jones N, Newburn M, Marshall S. User involvement in the development of a research bid: barriers, enablers and impacts. Health Expect. 2007;10(2):173-83.

14. Morgan LJ, Chambers R, Banerji J, Gater J, Jordan J. Consumers leading public consultation: the general public's knowledge of stroke. Fam Pract. 2005;22(1):8-14.

15. Barnes C, Oliver M, Barton L. Disability, the Academy and the Inclusive Society. In: Barnes C, Oliver M, Barton L, editors. Disability Studies Today. London (UK): Polity; 2002. p. 250-60.

16. Roy CM, Cain R. The involvement of people living with HIV/AIDS in community-based organizations: contributions and constraints. AIDS Care. 2001;13(4):421-32.

17. Patton C. Inventing AIDS. London (UK): Routledge; 1990.

18. National Health and Medical Research Council. A Model Framework for Consumer and Community Participation in Health and Medical Research. Canberra (AUST): Commonwealth of Australia; 2004.

19. Saunders C, Crossing S, Girgis A, Butow P, Penman A. Operationalising a model framework for consumer and community participation in health and medical research. Australian and New Zealand Health Policy. 2007:4:13.

20. Saunders C, Girgis A. Status, challenges and facilitators of consumer involvement in Australian health and medical research. Health Research Policy and Systems. 2010;8:34.

21. Denzin NK, Lincoln YS, editors. Handbook of Qualitative Research. London (UK): Sage Publications; 2000

22. Pope C, Mays N. Qualitative Research in Health Care. London (UK): BMJ Books; 2000.

23. Centre for Mental Health Research. Mission [Internet]. Canberra (AUST): Australian National University; 2011 [cited 2011 Jan 7]. Available from: http://cmhr.anu.edu.au/ index.php

24. The Cooperative Research Centre for Aboriginal and Torres Strait Islander Health. Cooperative Research Centre for Aboriginal Health, Approach to Research [Internet]. Melbourne (AUST): The Lowitja Institute; 2010 [cited 2011 Jan 11]. Available from: www.lowitja.org.au/crcah/approach-research
25. Gooda M, Brands J. Putting the users of research in the driver's seat: the Cooperative Research Centre for Aboriginal Health's new approach to research development. Australian Aboriginal Studies. 2006:2:27-35.

26. Telethon Institute for Child Health Research. Consumer and Community Participation Policy [Internet]. Perth (AUST): ICHR: 2011 [cited 2011 Jan 20]. Available from: http:// www.ichr.uwa.edu.au/files/docs/CCP\%20Policy.pdf

27. School of Population Health. Community and Consumer Involvement [Internet]. Perth (AUST): The University of Western Australia; 2011 [cited 2011 Jan 21]. Available from: www.sph.uwa.edu.au/community

28. Primary Health Care Research and Information Service. Primary Health Care Research and Information Service [Internet]. Adelaide (AUST): PHC RIS; 2011 [cited 2011 Jan 23]. Available from: http://www.phcris.org.au/

29. McKenzie A, Hanley B. Consumer and Community Participation in Health and Medical Research: A Practical Guide for Health and Medical Research Organisations [Internet]. Perth (AUST): The University of Western Australia; 2011 [cited 2011 Jan 19]. Available from: http://www.sph.uwa.edu.au/community/consumers-policy/guide

30. Cancer Voices. Cancer Voices NSW [Internet]. Greenwich (AUST): Cancer Voices NSW: 2011 [cited 2011 Jan 14]. Available from: www.cancervoices.org.au

31. Cancer Council NSW. Consumer Review Form and Guidelines [Internet]. Sydney (AUST): Cancer Council New South Wales; 2011 [cited 2011 Jan 17]. Available from: http://www.cancercouncil.com.au/html/research/researchapplications/downloads/ Consumer\%20Review\%20Guidelines\%202011.pdf

32. Saunders C, Girgis A, Butow P, Crossing S, Penman A. Beyond scientific rigour: funding cancer research of public value. Health Policy. 2007;84(2-3):234-42.

33. Saunders C, Crossing S, Girgis A, et al. Operationalising a model framework for consumer and community participation in health and medical research. Australian and New Zealand Health Policy. 2007;4 (1):13.

34. Health Issues Centre [Internet]. Melbourne (AUST): La Trobe University; 2011 [cited 2011 Jan 28]. Available from: http://www.healthissuescentre.org.au/

35. BrolgaNet [Internet]. Canberra (AUST): Centre for Mental Health Research, Australian National University; 2010 [cited 2011 Jan 24]. Available from: http://brolganet.anu. edu.au/

36. Victorian Cancer Agency [Internet]. Melbourne (AUST):Victorian Cancer Agency; 2010 [cited 2011 Jan 25]. Available from: www.victoriancanceragency.org.au/

37. Dear RF, Barratt AL, Crossing S, Butow PN, Hanson S, Tattersall MH. Consumer input into research: the Australian Cancer Trials website. Health Res Policy Syst. 2011 Jun 26:9(1):30.

38. School of Population Health. Involving People in Research Symposium 2008 [Internet]. Perth (AUST): University of Western Australia; 2010 [cited 2011 Jan 27]. Available from: http://www.sph.uwa.edu.au/community/involving-people

\section{Authors}

Carla Saunders, Afaf Girgis, Centre for Health Research \& Psychooncology (CHeRP), University of Newcastle, New South Wales

\section{Correspondence}

Carla Saunders, Centre for Health Research \& Psycho-oncology (CHeRP), University of Newcastle, Callaghan, New South Wales 2308; e-mail:carla.saunders@uon.edu.au 